\title{
Long-term outcome following laser therapy of benign cystic-solid thyroid nodules
}

\author{
Helle Døssing ${ }^{1,2}$, Finn Noe Bennedbæk ${ }^{3}$ and Laszlo Hegedüs ${ }^{2}$ \\ ${ }^{1}$ Department of Oto-rhino-laryngology and Neck Surgery, Odense University Hospital, Odense, Denmark \\ 2Department of Endocrinology and Metabolism, Odense University Hospital, Odense, Denmark \\ ${ }^{3}$ Department of Endocrinology and Metabolism, Herlev University Hospital, Herlev, Denmark
}

Correspondence should be addressed to H Døssing: helle.doessing@rsyd.dk

\begin{abstract}
Objective: Laser therapy (LT) is considered a safe and effective procedure for inducing thyroid nodule necrosis, fibrosis and shrinkage. Little is known about long-term efficacy of $L T$ in benign complex thyroid nodules, which we report here.

Design and methods: One hundred and ten euthyroid outpatients (28 men and 82 women; median age 48 years (range 17-82)) with a recurrent cytologically benign cystic ( $\geq 2 \mathrm{~mL}$ cyst volume) thyroid nodule causing local discomfort were assigned to LT. LT was performed after complete cyst aspiration and under continuous ultrasound (US) guidance. Nineteen patients ( 17 within 6 months) had surgery after LT. The median follow-up for the remaining 91 patients was 45 months (range: 12-134).

Results: The overall median nodule volume in the 110 patients decreased from $9.0 \mathrm{~mL}$ (range: $2.0-158.0)$ to $1.2 \mathrm{~mL}$ (range: $0.0-85.0)(P<0.001)$ at the final evaluation, corresponding to a median reduction of $85 \%$ (range: -49 to $100 \%$ ). Remission of the cystic part (volume $\leq 1 \mathrm{~mL}$ ) was obtained in 82 of 110 (75\%) patients after LT. The median cyst volume decreased from $6.3 \mathrm{~mL}$ (range: $2.0-158.0$ ) to $0.0 \mathrm{~mL}$ (range: 0.0-85.0) $(P<000.1)$, corresponding to a median reduction of $100 \%$ (range: -49 to $100 \%)$. These results correlated with a significant decrease in pressure as well as cosmetic complaints. Side effects were restricted to mild local pain.

Conclusion: US-guided aspiration and subsequent LT of benign recurrent cystic thyroid nodules results in a satisfactory long-term clinical response in the majority of patients. LT constitutes a clinically relevant alternative to surgery in such patients.
\end{abstract}

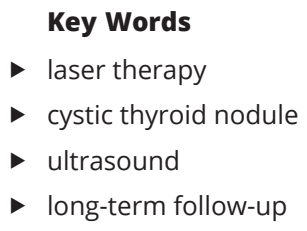

Endocrine Connections (2019) 8, 846-852

\section{Introduction}

Thyroid nodules are common in the adult population and according to several studies $15-30 \%$ of thyroid nodules are cystic or predominantly cystic (1). The incidence of thyroid cancer in cystic nodules is low and comparable or even lower to that of solid cold thyroid nodules $(2,3)$. The vast majority of thyroid cancers are solid or have a minimal (1-5\%) cystic component (4).

As thyroid carcinomas are rare, the reliance on risk stratification systems based on US features and fine-needle aspiration (FNA) is essential for an optimal management $(5,6)$. The use of US-guided FNA from the solid part of the mixed cystic and solid nodule can reduce the number of insufficient biopsies, which has been shown to improve the diagnostic accuracy $(4,7)$. Pressure symptoms or cosmetic complaints may be an indication for treatment, and nonsurgical treatment has been used for several years (8). Although simple aspiration of the cystic part may reduce the pressure-related symptoms and carries a very low risk of side effects, the recurrence rate is on average around $50 \%$ (range: 10-80\%), dependent on the number of aspirations and the cyst volume (9). 
Over the last decade, US-guided minimally invasive ablative therapies have gained widespread attention as methods for treating benign thyroid nodules and cysts $(10,11,12,13,14,15)$. These techniques include thermal techniques as well as percutaneous ethanol sclerotherapy (PEI). As an alternative to PEI and a way to reduce the side effects associated with treating the solid part of the nodule (16), LT has, in randomized studies, shown promising results $(17,18,19)$. However, data on long-term efficacy after LT are limited and restricted to solid nodules $(20,21)$. Therefore, we evaluated the remission rate in recurrent benign predominantly cystic thyroid nodules and nodule-related symptoms in a consecutive group of patients treated with LT followed for at least 1 year and on average around 4 years.

\section{Patients and methods}

One hundred and ten (82 females and 28 males with a median age of 48 years (range 17-82)) euthyroid outpatients with a cytologically benign, scintigraphically cold, and ultrasonographically (US) cystic-solid thyroid nodule were assigned to LT. All had cosmetic and/or pressure symptoms. Furthermore, all had recurrence of the cystic part after the initial diagnostic aspiration. Clinically, there was neither suspicion of nor a family history of thyroid cancer. None had had prior radiation to the neck. Blood tests included serum thyrotropin (TSH) (normal range, $0.3-4.0 \mathrm{mU} / \mathrm{mL}$ ), serum total thyroxine (T4) (normal range, $65-135 \mathrm{mmol} / \mathrm{L}$ and serum total triiodothyronine (T3) (normal range, $1.00-2.10 \mathrm{mmol} / \mathrm{L}$ ).

LT was carried out on an out-patient basis. At enrolment and at the final evaluation, the patients were asked to rate pressure symptoms and cosmetic complaints on a visual $10 \mathrm{~cm}$ analogue scale $(0-10)$, as used a multitude of times in previous studies $(18,19,20,22)$. The patients were investigated 1, 3 and 6 months after the treatment and then annually. Initially, and during the follow-up, cyst volume, volume of the solid part and total thyroid volume, by US, as well as serum thyroid hormones and serum TSH were investigated. Recurrence of the cystic part was defined as a volume of more than $1 \mathrm{~mL}$ (determined by US). The initial cyst volume was calculated by US, and this result was compared with the aspirated volume. The volume of the nodules was calculated by measuring the three largest perpendicular diameters (length $\times$ width $\times$ depth $\times \pi / 6$ ).

LT was performed under sterile conditions, guided by US, and preceded by local anesthesia with lidocaine $(10 \mathrm{mg} / \mathrm{mL})$. The steering needle (18 gauge $(1.2 \mathrm{~mm}))$ was positioned in the cystic part of the thyroid nodule. When this was completely aspirated, the steering needle was left in situ and the laser fiber ( $0.4 \mathrm{~mm}$ in diameter) was positioned in order to induce necrosis and destroy the cyst membrane and the solid part of the nodule. The entire procedure was performed under continuous US guidance using a high-frequency linear transducer (Philips L18-5). The output power was between 1.5 and $3.0 \mathrm{~W}$ and depended on the size of the solid part of the nodule. The laser power source was a continuous-wave infrared $(820 \mathrm{~nm})$ diode (model 15; Diomed, Cambridge, England) laser. The vapor was clearly visible on US as an irregular hyperechogenic area enlarging over time, and the procedure was typically terminated when this area was stationary in size or based on patient discomfort and/or pain.

The protocol was approved by the Ethics Committee of Funen (journal no.81 20070124), and consent has been obtained from each patient after full explanation of the purpose of the study.

\section{Statistical analyses}

Results for continuous data are given as medians and ranges. All comparisons for paired data are based on ANOVA II (observations based on within-subject difference; serial measurements). A backward step-wise logistic regression was employed for analyzing potential variables predictive for outcome. A $P$ value $<0.05$ was considered significant. Pressure symptoms and cosmetic complaints were rated on a $0-10 \mathrm{~cm}$ visual analogue scale (VAS) and compared with the initial score, and with changes evaluated by a sign test. The statistical analyses were performed using the SPSS statistical software, version 25.0 (SPSS).

\section{Results}

The median total energy delivered in the 110 patients was 1200J (range: 94-4392), corresponding to 122J (range: 14-733) per $\mathrm{mL}$ of initial nodule tissue. There was no significant difference between the operated group (median 1200J (range: 94-4392J)) and the non-operated group (median 1200J (range: 478-2300)) $(P=0.8)$. The median duration of the LT treatment was 600s (range: 47-1545). The median duration of self-reported symptoms was 6 months (range: 2-60) and did not differ between the operated and non-operated group.

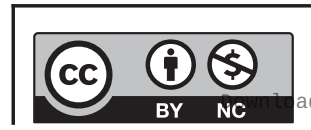

This work is licensed under a Creative Commons Attribution-NonCommercial 4.0 International License. ded from Bioscientifica.com at 04/26/2023 02:08:52PM via free access 


\section{Treatment outcomes}

110 patients, of whom 22 were recruited for a randomized trial (19) were assigned to LT (Fig. 1). The overall median nodule volume decreased from $9.0 \mathrm{~mL}$ (range: $2-158)$ to $1.2 \mathrm{~mL}$ (range: $0-85)(P<0.001)$. Remission of the cystic part (volume $\leq 1 \mathrm{~mL}$ ) was obtained in 82 of $110(75 \%)$ patients after LT. Nineteen patients (17 within 6 months and 2 patients after 36 months) had surgery after LT and the median follow-up for the remaining 91 patients was 45 months (range: 12-134).

\section{Results for patients in the surgery group}

The decision of subsequent surgery was based on persistent nodule-related compressive symptoms and/or cosmetic deformity in 19 of 110 patients (17\%). The median total nodule volume reduction in the 19 patients who had surgery decreased from $22.4 \mathrm{~mL}$ (range: 5.0-68.0) to $19.4 \mathrm{~mL}$ (range: $3.0-70.0)(P=0.05)$. Median reduction in cyst volume was from $20 \mathrm{~mL}$ (range: $2.0-68.0$ ) to $18 \mathrm{~mL}$ (range: $0-70)(P=0.03)$ while the solid part diminished insignificantly from $2.0 \mathrm{~mL}$ (range: $0.0-7.2$ ) to $1.5 \mathrm{~mL}$ (range: $0.0-10.7)(P=0.7)$. In these 19 patients, there was neither reduction in self-reported pressure symptoms (from median 5.0 (range: 0.0-9.0) to 5.0 (range: 0.0-8.0) after LT $(P=0.5)$ ), nor in cosmetic complaints (from median 4.0 to 4.0 (range: 0.0-9.0) $(P=0.5)$ ). Although there was a significant reduction in cyst- and nodule volume, this was insufficient in alleviating the selfestimated symptoms. Eighteen of these patients had more than one cyst aspiration before LT, the median number being 3 (range $2-5$ ).

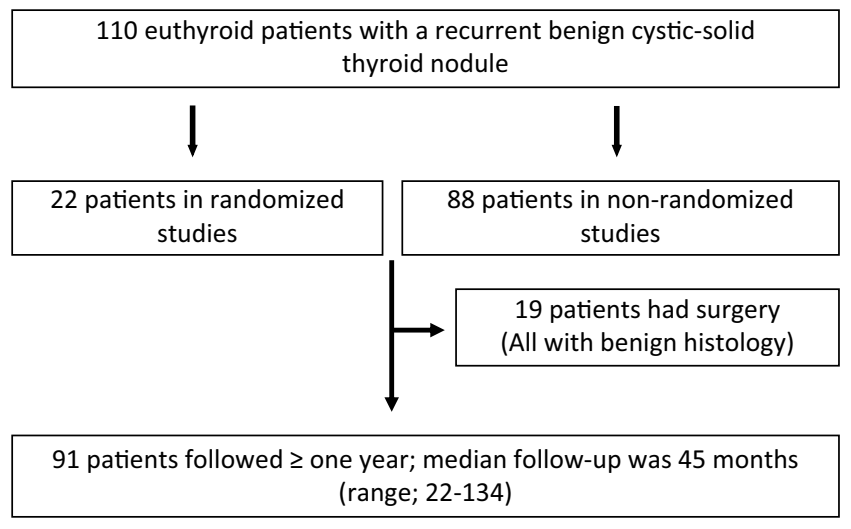

Figure 1

Algorithm for enrolment of study patients, in this long-term follow-up after LT therapy, for a benign cystic-solid thyroid nodule.

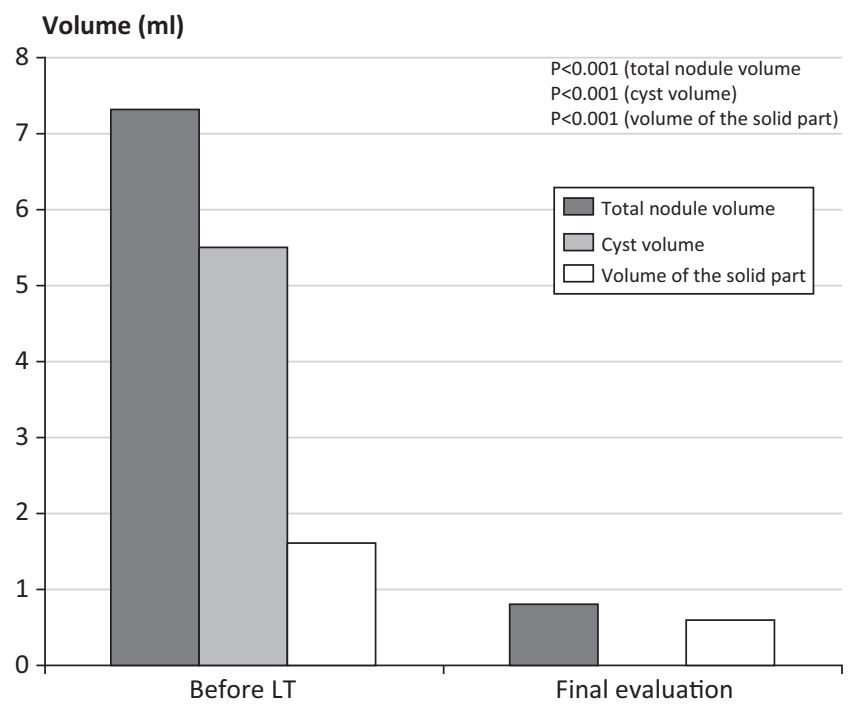

Figure 2

Total nodule volume, cyst volume and volume of the solid part of the nodule before LT and at final evaluation for the 91 patients in the non-surgery group (median values).

\section{Results for patients in the non-surgery group}

The overall median nodule volume in these 91 patients decreased from $7.3 \mathrm{~mL}$ (range: $2.0-50.0$ ) to $0.8 \mathrm{~mL}$ (range: 0.0-16.1) $(P<0.001)$ (Fig. 2), corresponding to a reduction of $92 \%$ (range: -10 to $100 \%$ ). The median cyst volume decreased from $5.5 \mathrm{~mL}$ (range: $2.0-45.0$ ) to $0.0 \mathrm{~mL}$ (range: 0.0-5.0) $(P<0.001)$, corresponding to a median reduction of $100 \%$ (range: $43-100 \%$ ), and the solid part decreased from $1.6 \mathrm{~mL}$ (range: $0.0-17.0$ ) to $0.6 \mathrm{~mL}$ (range: $0.0-0.6$ ) $(P<0.001)$ (Fig. 3). Cure of the cystic part, defined as a cyst volume $\leq 1 \mathrm{ml}$, was achieved in 80 of 91 patients $(88 \%)$.

In this group, 18 patients had more than one (in fact two) aspiration of the cystic part before LT. Eleven patients with a cyst volume $>1 \mathrm{~mL}$ were not cured as for the cystic part. Before LT, median cyst volume in these patients was $10 \mathrm{~mL}$ (range 3-40 mL), which decreased to $1.6 \mathrm{~mL}$ (range 1.5-15 mL) $(P<0.05)$ following LT.

According to self-estimated ratings, on a VAS from 0 to $10 \mathrm{~cm}$, median pressure symptoms in the 91 patients were reduced from 5.0 (range: 0.0-9.0) to 0.0 (range: 0.0-5.0) $(P<0.001)$ and cosmetic complaints from 1.0 (range: $0.0-10.0)$ to 0.0 (range: $0.0-2.0)(P<0.001)$ (Fig. 3).

The only side effect after LT was slight to moderate pain in 71 patients. The median duration of the pain was $2 \pm 1.5$ days (range: $0-5$ ) treated with mild analgesics in 28 patients. There were no other side effects such as laryngeal nerve injury, fever, haematomas or thyroid dysfunction.

The only parameter which significantly affected the cure rate of the cystic part of the thyroid nodule was the

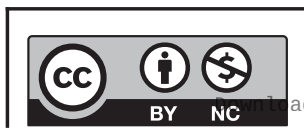

This work is licensed under a Creative Commons Attribution-NonCommercial 4.0 International License. ded from Bioscientifica.com at 04/26/2023 02:08:52PM 


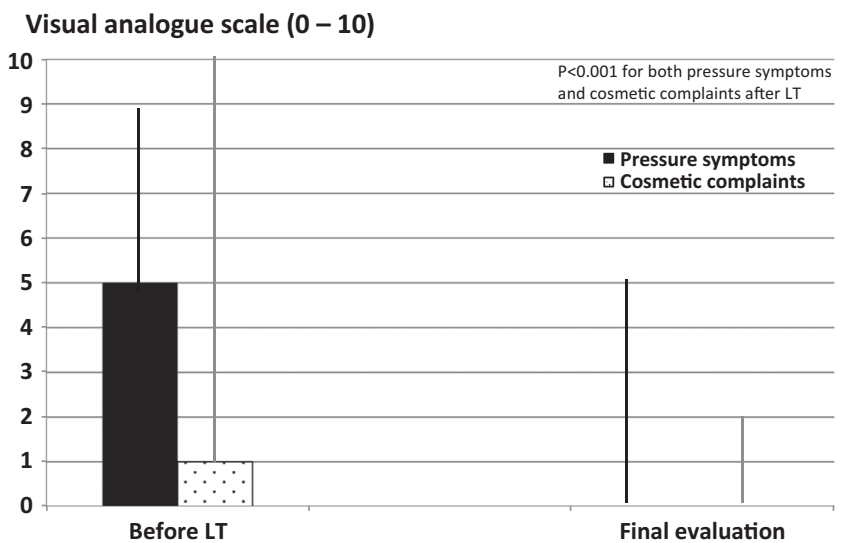

Figure 3

Visual analogue scale for both pressure symptoms and cosmetic complaints before and after LT in the 91 patients in the non-surgery group (median values).

number of aspirations before LT, in that a higher number of aspirations decreased the chance of success. The initial nodule and cyst volume, total energy delivered, energy delivered per $\mathrm{mL}$ nodule tissue, number of LT sessions and treatment duration had no influence on the outcome (Table 1).

\section{Discussion}

Over the last 10-15 years LT has increasingly, together with other thermal ablation techniques, been accepted as an alternative to surgery in selected patients with benign nodular thyroid disease $(13,18,19,23,24)$. LT has proven efficacious in nonfunctioning thyroid nodules, also in the long-term $(20,25)$. In cystic thyroid nodules, aspiration alone may be of therapeutic value, but the effect varies considerably, and recurrence is very prevalent and seen in up to $80 \%$ of patients (1). Levothyroxine is without effect (1) and ethanol sclerotherapy, although efficacious (1),

Table 1 Multivariate analysis of variables affecting treatment success (cure of the cystic part $\leq 1 \mathrm{~mL}$ ).

\begin{tabular}{|c|c|c|}
\hline Variable & $\begin{array}{c}\text { Confidence } \\
\text { interval } \\
\end{array}$ & $P$ value \\
\hline Total nodule volume & $0.86-1.43$ & 0.9 \\
\hline Cyst volume & $0.74-1.21$ & 0.7 \\
\hline Previous aspiration ${ }^{a}$ & $1.82-5.80$ & 0.001 \\
\hline Total energy delivered & $0.99-1.00$ & 0.5 \\
\hline Energy delivered per $\mathrm{ml}$ nodule volume & $0.99-1.00$ & 0.5 \\
\hline Treatment duration & $0.99-1.00$ & 0.5 \\
\hline No of LT sessions & $0.3-4.7$ & 0.7 \\
\hline Duration of symptoms & $0.16-0.21$ & 0.4 \\
\hline
\end{tabular}

${ }^{a}$ Number of aspirations before inclusion. carries the risk of seepage of the ethanol along the needle-tract and potential side effects based on extrathyroidal fibrosis and/or affection of the recurrent laryngeal nerves (26). The effect of LT in solid nodules is well documented but only few studies have reported the outcome in cystic-solid (mixed) nodules (26).

In this long-term follow-up study, we show that LT is effective in such patients and that the vast majority obtain cure of the relapsing cystic part of their thyroid nodule. At the final evaluation, a median reduction of the total nodule volume of $92 \%$ was achieved and remission of the cystic part (volume $\leq 1 \mathrm{~mL}$ ) was obtained in 82 of 110 (75\%) patients. Furthermore, a significant reduction of the solid part of the nodule was also obtained, although this was only a small part of the entire complex nodule. Of the 110 patients, 19 (17\%) had subsequent surgery because of an unsatisfactory result after LT therapy. This was mainly due to unaltered pressure symptoms and/or cosmetic complaints and possibly related to the persistence of a prominent solid part. Pre-treatment total nodule volume in this group with treatment failure was significantly larger than in the non-surgery group (median $22.4 \mathrm{~mL}$ vs $7.3 \mathrm{~mL} ; P<0.001)$, but in a multivariate analysis of variables affecting treatment success (meaning cure of the cystic part), only multiple pre-LT aspirations predicted lower success rate. Therefore, results from the current study offer little help in selecting which complex nodules are the best candidates for LT.

Termination of treatment in each LT session, when treating solid nodules, is largely guided by achieving a decreased and often obliterated vascularization within the nodule. However, in the heterogeneous cystic/solid nodules termination relies mostly on the echogenic changes not evolving further. This obviously involves a large degree of operator-dependent variability and is a weakness when defining criteria for a LT treatment protocol. Furthermore, if the remnant solid part - after the cyst fluid has been emptied - is in close proximity to the carotid artery or posterior border, it limits the area where positioning the laser fiber will most likely result in adequate energy delivered. Increasing output power induces burning pain during LT (13) and increases the risk of carbonization of the fiber. Moreover, transient vocal cord palsy has been described when more than one fiber has been used (23). Finally, using two or more fibers results in a poorer real-time US overview of the actual extent of thermal necrosis and was therefore not considered by us in this study.

Pain is the most common complaint during and following LT $(27,28)$. In our studies, pain was mild or

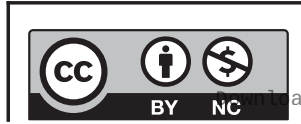

This work is licensed under a Creative Commons Attribution-NonCommercial 4.0 International License. ded from Bioscientifica.com at 04/26/2023 02:08:52PM 
moderate and the patients could leave the out-patient clinic just after the LT procedure. As opposed to others $(23,28)$, we have not encountered any serious side effects, such as damage to the laryngeal nerves, subcapsular hematomas or cervical swelling. The explanation could be the difference in the output power and a different approach by us using only one fiber. In one study, vocal cord paresis was reported in $1.6 \%$ of treated patients (29), but it could be an underestimation as laryngoscopy was not routinely performed, in contrast to our practice. Importantly, thyroid function was unaltered in all of our patients during follow-up and it is also reassuring that a benign histology was found in all 19 patients who subsequently underwent surgery.

Laser treatment is a low-cost procedure and can be performed by a team of one to two physicians and a nurse in an out-patient setting. The duration of a complete session rarely exceeds $30 \mathrm{~min}$. This definitely favors LT to other minimally invasive techniques. Other thermal ablation methods, such as radio frequency ablation (RFA), has been compared to percutaneous ethanol sclerotherapy (PEI), where PEI was superior compared to RFA in cystic thyroid nodules (30). Similar volume reduction was reported with PEI compared to RFA. However, limitations using PEI are the non-predictable diffusion of the ethanol in treating the solid part of the nodule, potentially causing extraglandular fibrosis and moderate to severe pain (12). In disfavor of RFA is the higher expense (30).

In a randomized study, PEI resulted in remission in $68 \%$ of cystic thyroid nodules after one injection (31). However, the risk of side effects related to PEI, including extraglandular fibrosis, which may impede subsequent surgery in case of treatment failure $(16,32)$, has prompted clinical studies on the efficacy of LT in the management of relapsing cystic nodules $(19,22)$. The advantage of LT is that the damage can better be restricted to the ablated area without extranodular tissue damage. However, RFA seems to be superior in reducing the nodule volume compared to LT, when applied to solid nodules. Although limited, compared to LT, side effects may be more common with RFA $(19,20,27)$. The main shortcomings of these techniques are limited availability, few longterm follow-up studies and the considerable operator dependency, but also the lack of randomized studies comparing nonsurgical treatment with surgery $(33,34)$.

The cure rate of $80 \%$ ( 8 of 10 patients) in a pilot LT study (22), followed by short-term data from a randomized prospective study (19), as well as the present long-term follow-up of 110 patients resulting in a cure rate (cyst volume $\leq 1 \mathrm{~mL}$ ) of overall
$75 \%$ (82 of 110 patients) confirms the efficacy of LT in this thyroid phenotype. While LT is not as effective as surgery it is a relevant alternative treatment in patients with a solidcystic thyroid nodule, extending the data from our group $(18,27)$ and those of Pacella et al. (23). Efficacy is high and significantly better than with aspiration alone (18\%) and is of the order obtained with PEI (31). As opposed to PEI, no extranodular damage was observed, and pain was milder, whereas the reduction of the solid nodule component was preserved, and self-evaluated pressure symptoms vanished in the vast majority, resulting in improved quality of life. In a retrospective nonrandomized study, RFA performed similar to PEI but treatment duration was longer and was considerably more expensive $(8,30)$.

\section{Conclusion}

LT is a minimally invasive, safe and low-cost procedure resulting in a satisfactory long-term (median 45 months) efficacy in four of five patients with a benign cystic-solid nodule. It is a clinically relevant alternative to surgery in selected patients, not least due to improved patientrelated quality of life and minimal side effects. Therefore, we suggest that LT be added to the therapy algorithm for this condition as a cost-effective alternative in selected patients. The disadvantage is the considerable operator dependency and lack of a histological assessment. Future studies should focus on comparing minimal invasive procedures with surgery and incorporate dedicated instruments, such as the ThyPRO (35), for the evaluation of quality of life.

\section{Declaration of interest}

The authors declare that there is no conflict of interest that could be perceived as prejudicing the impartiality of the research reported.

\section{Funding}

This research did not receive any specific grant from any funding agency in the public, commercial or not-for-profit sector.

\section{Author contribution statement}

Idea, preparation of the final protocol and manuscript draft: $H D, L ~ H$ and F N B. LT treatment: H D and L H.

\section{References}

1 Hegedüs L, Bonnema SJ \& Bennedbæk FN. Management of simple nodular goiter: current status and future perspectives. Endocrine Reviews 200324 102-132. (https://doi.org/10.1210/er.2002-0016)

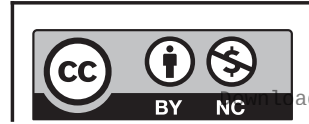

This work is licensed under a Creative Commons Attribution-NonCommercial 4.0 International License. ded from Bioscientifica.com at 04/26/2023 02:08:52PM 
2 Jayesh SR, Mehta P, Cherian MP, Ilayaraja V, Gupta P \& Venkatesh K. Efficacy and safety of USG-guided ethanol sclerotherapy in cystic thyroid nodules. Indian Journal of Radiology and Imaging 200919 199-202. (https://doi.org/10.4103/0971-3026.54879)

3 Paschke R, Hegedüs L, Alexander E, Valcavi R, Papini E \& Gharib H. Thyroid nodule guidelines: agreement, disagreement and need for future research. Nature Reviews: Endocrinology 20117 354-361. (https://doi.org/10.1038/nrendo.2011.1)

4 Henrichsen TL, Reading CC, Charboneau JW, Donovan DJ, Sebo TJ \& Hay ID. Cystic change in thyroid carcinoma: prevalence and estimated volume in 360 carcinomas. Journal of Clinical Ultrasound 201038 361-366. (https://doi.org/10.1002/jcu.20714)

5 Durante C, Grani G, Lamartina L, Filetti S, Mandel SJ \& Cooper DS. The diagnosis and management of thyroid nodules: a review. JAMA 2018319 914-924. (https://doi.org/10.1001/jama.2018.0898)

6 Russ G, Bonnema SJ, Erdogan MF, Durante C, Ngu R \& Leenhardt L. European Thyroid Association guidelines for ultrasound malignancy risk stratification of thyroid nodules in adults: the EU-TIRADS. European Thyroid Journal 20176 225-237. (https://doi. org/10.1159/000478927)

7 Filetti S, Durante C \& Torlontano M. Nonsurgical approaches to the management of thyroid nodules. Nature Clinical Practice: Endocrinology and Metabolism 20062 384-394. (https://doi. org/10.1038/ncpendmet0215)

8 Gharib H, Hegedüs L, Pacella CM, Baek JH \& Papini E. Clinical review: nonsurgical, image-guided, minimally invasive therapy for thyroid nodules. Journal of Clinical Endocrinology and Metabolism 2013 98 3949-3957. (https://doi.org/10.1210/jc.2013-1806)

9 Bennedbæk FN, Karstrup S \& Hegedüs L. Percutaneous ethanol injection therapy in the treatment of thyroid and parathyroid diseases. European Journal of Endocrinology 1997136 240-250. (https://doi.org/10.1530/eje.0.1360240)

10 Bennedbæk FN, Nielsen LK \& Hegedüs L. Effect of percutaneous ethanol injection therapy versus suppressive doses of L-thyroxine on benign solitary solid cold thyroid nodules: a randomized trial. Journal of Clinical Endocrinology and Metabolism 199883 830-835. (https:// doi.org/10.1210/jcem.83.3.4673)

11 Døssing H, Bennedbæk FN \& Hegedüs L. Ultrasound-guided interstitial laser photocoagulation of an autonomous thyroid nodule: the introduction of a novel alternative. Thyroid 200313 885-888. (https://doi.org/10.1089/105072503322401104)

12 Guglielmi R, Pacella CM, Bianchini A, Bizzarri G, Rinaldi R, Graziano FM, Petrucci L, Toscano V, Palma E, Poggi M, et al. Percutaneous ethanol injection treatment in benign thyroid lesions: role and efficacy. Thyroid 200414 125-131. (https://doi. org/10.1089/105072504322880364)

13 Pacella CM, Bizzarri G, Spiezia S, Bianchini A, Guglielmi R, Crescenzi A, Pacella S, Toscano V \& Papini E. Thyroid tissue: US-guided percutaneous laser thermal ablation. Radiology 2004232 272-280. (https://doi.org/10.1148/radiol.2321021368)

14 Valcavi R \& Frasoldati A. Ultrasound-guided percutaneous ethanol injection therapy in thyroid cystic nodules. Endocrine Practice 2004 10 269-275. (https://doi.org/10.4158/EP.10.3.269)

15 Zingrillo M, Torlontano M, Ghiggi MR, Frusciante V, Varraso A, Liuzzi A \& Trischitta V. Radioiodine and percutaneous ethanol injection in the treatment of large toxic thyroid nodule: a longterm study. Thyroid 200010 985-989. (https://doi.org/10.1089/ thy.2000.10.985)

16 Bennedbæk FN \& Hegedüs L. Percutaneous ethanol injection therapy in benign solitary solid cold thyroid nodules: a randomized trial comparing one injection with three injections. Thyroid 19999 225-233. (https://doi.org/10.1089/thy.1999.9.225)

17 Døssing H, Bennedbæk FN \& Hegedüs L. Effect of ultrasoundguided interstitial laser photocoagulation on benign solitary solid cold thyroid nodules - a randomised study. European Journal of Endocrinology 2005152 341-345. (https://doi.org/10.1530/ eje.1.01865)

18 Døssing H, Bennedbæk FN \& Hegedüs L. Effect of ultrasoundguided interstitial laser photocoagulation on benign solitary solid cold thyroid nodules: one versus three treatments. Thyroid 200616 763-768. (https://doi.org/10.1089/thy.2006.16.763)

19 Døssing H, Bennedbæk FN \& Hegedüs L. Interstitial laser photocoagulation (ILP) of benign cystic thyroid nodules - a prospective randomized trial. Journal of Clinical Endocrinology and Metabolism 2013 98 E1213-E1217. (https://doi.org/10.1210/jc.2013-1503)

20 Døssing H, Bennedbæk FN \& Hegedüs L. Long-term outcome following interstitial laser photocoagulation of benign cold thyroid nodules. European Journal of Endocrinology 2011165 123-128. (https://doi.org/10.1530/EJE-11-0220)

21 Papini E, Pacella CM, Misischi I, Guglielmi R, Bizzarri G, Døssing H $\&$ Hegedüs L. The advent of ultrasound-guided ablation techniques in nodular thyroid disease: towards a patient-tailored approach. Best Practice and Research: Clinical Endocrinology and Metabolism 201428 601-618. (https://doi.org/10.1016/j.beem.2014.02.004)

22 Døssing H, Bennedbæk FN \& Hegedüs L. Beneficial effect of combined aspiration and interstitial laser therapy in patients with benign cystic thyroid nodules: a pilot study. British Journal of Radiology 200679 943-947. (https://doi.org/10.1259/bjr/40698061)

23 Pacella CM, Mauri G, Achille G, Barbaro D, Bizzarri G, De Feo P, Di Stasio E, Esposito R, Gambelunghe G, Misischi I, et al. Outcomes and risk factors for complications of laser ablation for thyroid nodules: a multicenter study on 1531 patients. Journal of Clinical Endocrinology and Metabolism 2015100 3903-3910. (https://doi.org/10.1210/ jc.2015-1964)

24 Papini E, Bizzarri G \& Pacella CM. Percutaneous laser ablation of benign and malignant thyroid nodules. Current Opinion in Endocrinology, Diabetes, and Obesity 200815 434-439. (https://doi. org/10.1097/MED.0b013e32830eb89a)

25 Papini E, Rago T, Gambelunghe G, Valcavi R, Bizzarri G, Vitti P, De Feo P, Riganti F, Misischi I, Di Stasio E, et al. Long-term efficacy of ultrasound-guided laser ablation for benign solid thyroid nodules Results of a three-year multicenter prospective randomized trial. Journal of Clinical Endocrinology and Metabolism 201499 3653-3659. (https://doi.org/10.1210/jc.2014-1826)

26 Nixon IJ, Angelos P, Shaha AR, Rinaldo A, Williams MD \& Ferlito A. Image-guided chemical and thermal ablations for thyroid disease: review of efficacy and complications. Head and Neck $2018 \mathbf{4 0}$ 2103-2115. (https://doi.org/10.1002/hed.25181)

27 Baek JH, Lee JH, Sung JY, Bae JI, Kim KT, Sim J, Baek SM, Kim YS, Shin JH, Park JS, et al. Complications encountered in the treatment of benign thyroid nodules with US-guided radiofrequency ablation: a multicenter study. Radiology 2012262 335-342. (https://doi. org/10.1148/radiol.11110416)

28 Gambelunghe G, Bini V, Monacelli M, Avenia N, D'Ajello M, Colella R \& De Feo P. The administration of anesthetic in the thyroid pericapsular region increases the possibility of side effects during percutaneous laser photocoagulation of thyroid nodules. Lasers in Surgery and Medicine 201345 34-37. (https://doi.org/10.1002/ lsm.22110)

29 Valcavi R, Riganti F, Bertani A, Formisano D \& Pacella CM. Percutaneous laser ablation of cold benign thyroid nodules: a 3-year follow-up study in 122 patients. Thyroid 201020 1253-1261. (https://doi.org/10.1089/thy.2010.0189)

30 Sung JY, Kim YS, Choi H, Lee JH \& Baek JH. Optimum firstline treatment technique for benign cystic thyroid nodules: ethanol ablation or radiofrequency ablation? American Journal of Roentgenology 2011196 W210-W214. (https://doi.org/10.2214/ AJR.10.5172)

31 Bennedbæk FN \& Hegedüs L. Treatment of recurrent thyroid cysts with ethanol: a randomized double-blind controlled trial. Journal of https://ec.bioscientifica.com https://doi.org/10.1530/EC-19-0236 (c) 2019 The authors Published by Bioscientifica Ltd

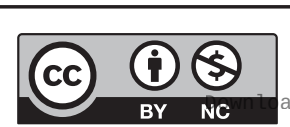

This work is licensed under a Creative Commons Attribution-NonCommercial 4.0 International License. ded from Bioscientifica.com at 04/26/2023 02:08:52PM 
Clinical Endocrinology and Metabolism 200388 5773-5777. (https:// doi.org/10.1210/jc.2003-031000)

32 Bennedbæk FN \& Hegedüs L. Alcohol sclerotherapy for benign solitary solid cold thyroid nodules. Lancet 1995346 1227. (https:// doi.org/10.1016/S0140-6736(95)92930-4)

33 Hegedüs L. Therapy: a new nonsurgical therapy option for benign thyroid nodules? Nature Reviews: Endocrinology 20095 476-478. (https://doi.org/10.1038/nrendo.2009.152)

34 Pacella CM, Mauri G, Cesareo R, Paqualini V, Cianni R, De Feo P, Gambelunghe G, Raggiunti B, Tina D, Deandrea M, et al.
A comparison of laser with radiofrequency ablation for the treatment of benign thyroid nodules: a propensity score matching analysis. International Journal of Hyperthermia 201733 911-919. (https://doi.org/10.1080/02656736. 2017.1332395)

35 Watt T, Hegedüs L, Groenvold M, Bjorner JB, Rasmussen AK, Bonnema SJ \& Feldt-Rasmussen U. Validity and reliability of the novel thyroid-specific quality of life questionnaire, ThyPRO. European Journal of Endocrinology 2010162 161-167. (https://doi.org/10.1530/ EJE-09-0521)

Received in final form 14 May 2019

Accepted 4 June 2019

Accepted Preprint published online 4 June 2019
This work is licensed under a Creative Commons Attribution-NonCommercial 4.0 International License. 